\title{
PTSD and Action
}

\author{
Ladislav Valach, Ph.D* \\ Private practice, Switzerland
}

\begin{abstract}
Trying to understand, diagnose, conceptualize and treat Post-traumatic stress disorder (PTSD) leads to a range of ideas and propositions reaching from a simple reaction to a meaningful dealing with threat expectations. While the theories of PTSD are centered around one specific segment of human behavior (e.g. conditioning or coping) many treatment programs are eclectic. It is suggested that conceptualizing processes involved in PTSD in terms of an action theory informed frame of reference would allow to devise an integrative understanding of PTSD, integrative theory of the target processes and, finally, a theory-based treatment integrating the individual techniques in a well-reasoned system. The contextual action theory is suggested as an alternative satisfying the criteria required by the integration proposition.
\end{abstract}

\section{Introduction}

Mental health problems following an existentially threatening experience were recognized as common in the last century and post-traumatic stress has been assessed as requiring a diagnosis as a disorder (PTSD) in its own right. These problems, the PTSD diagnosis and treatment, received much professional attention and attracted substantial research and conceptual interest [1]. However, in Switzerland and in Europe in general this occurred only in the last 30 years, as PTSD was under diagnosed in the early nineties [2].

Encountering a number of patients diagnosed with PTSD in the psychotherapy practice and elsewhere [2-5] studying PTSD diagnosed victims of torture [6-11] and participating in conceptual development and research on human behavior $[12,13]$ motivates this sharing of some of the considerations about PTSD symptoms and their understanding.

PTSD symptoms are usually grouped into four types [14]: The four symptom clusters are intrusions (Criterion B), avoidance (Criterion $C$ ), negative alterations in cognitions and mood (NACM; Criterion D), and alterations in arousal and reactivity (Criterion E). Along with the criticism of the psychometric problems in its reflecting clinical practice [15] these criteria have further been scrutinized [16]. The authors reviewed the literature on PTSD's assumptions and attempts to validate the construct and concluded that the core assumptions and hypothesized mechanisms lacked empirical support.

The PTSD symptoms can be assessed whether they refer to passive or active processes. Intrusive memories and changes in physical and emotional reactions seem to be passive experiences, avoidance could be seen as an active coping strategy and negative changes in thinking and mood could be both - passive reactions or active changes. In addition, the majority of these symptoms are described as inner-psychological pro- cesses with the exception of physical reaction, which could be restricted to autonomic nervous system responses. However, the experience of the encounters with these patients in the psychotherapy practice teaches, that these people complain about their inability to lead their everyday life. Their daily actions are substantially disordered and restricted [17-19]. Equally, their inner processes are related to some actions and contexts and cannot be treated as context-free dispositional universals. In fact, it has been shown that PTSD individuals when monitored in their daily activities do not show less positive affect than individuals without PTSD but only show a higher level of negative affect [20]. Consequently, it would be helpful if we possessed a clear conceptualization of everyday actions and the role that the processes described as symptoms of PTSD play in them. In other words, the question is: Is PTSD comparable to a toothache that impacts our daily life for a long time if not dealt with, but could be treated independently of our daily life. Or is PTSD a part of our daily thinking and behaving and must be treated through our daily thoughts and behavior.

\section{Post-Traumatic Stress Disorder Symptoms within an Action}

Facing these open questions and problems in understanding PTSD we propose the contextual action theory [21] based on the theory of goal- directed action [22] as a conceptual backdrop for dealing with PTSD symptoms. In this view,

*Corresponding author: Ladislav Valach, Private practice, Lindenstrasse 26, 3047 Bremgarten b. Bern, Switzerland

Accepted: February 13, 2021

Published online: February 15, 2021

Citation: Valach L (2021) PTSD and Action. J Depress Anxiety Disord 3(1):68-75 
the basic unit of analysis is an action. It is a short-term unit segmented out of the stream of behavior by a goal (experienced, defined, attributed). Thus, the subjective experience is as important as the definition by a professional observer and the attribution by a naïve observer [23]. Consequently, in order to understand the PTSD, we would require subjective experiences of and in actions. These subjective experiences would be a part of observable actions and would also be understood in meaningful terms by other members of the same communication community. We are all engaged in actions from the moment of waking until the time of falling asleep. Even the seemingly passive moments of doing nothing are actions. They can be experienced, systematically defined and observed; a naïve bystander would also make sense of these activities. Combining these three data sets provides a comprehensive picture of PTSD symptoms in actions: Subjective experiences within manifest action that is socially accessible. Action is not just a series of movements towards a goal. Action is a system organized in a hierarchy and a sequence with many parallel processes. From a professional observer point of view, we define a goal in meaningful terms [24], then we can identify a number of action steps in a functional way (how they contribute toward the goal) and, finally, we can describe the manifest behavior in physical terms. From the subjective point of view, we have a conscious, or by attention accessible, goal, equally we have accessible subjective processes occurring while we progress towards the goal and, finally, only with additional means conscious and attentionally accessible movements and other regulation processes of the action elements. While these action organization levels are described in their ideal-type way, they have to be understood as hierarchies on their own, such as goal hierarchy, hierarchy in the sequences depending on the complexities of the objects we deal with etc. In close relation to this conceptualization the processes of steering, control and regulation could be understood as linked to goals (steering), to action steps (action control) and to action elements (regulation). In addition, the processes of self-monitoring, and action-monitoring and action energization are equally important. A further detailed and systematic description of the contextual action theory can be found elsewhere $[12,13]$.

With this very basic understanding of an action, we can approach the PTSD symptoms. However, it is important to understand that in the system of action the systemic process and, therefore, also a systemic causality is assumed. Thus, it is not a single variable determining forever the processes of an action. An action might originate in one segment of action but this process becomes a part of a number of other processes involved.

We can follow this with the example of what is identified as intrusive memory.

Patients might complain that while sitting down to relax the traumatizing experience comes to their attention. Thus, instead of enjoying a relaxing look out of the window and remembering the last successful and satisfying experience, the traumatizing episode comes to mind. The mind and body relaxation intention cannot materialize, because thoughts of the negative experience bring negative emotions, the body becomes tense, the breathing shallow and the biochemistry changes. Instead of relaxation patients experience stress. Thus, the patients are not able to successfully perform relaxing actions in the way they are used to. However, this process could start in many different ways. Such as seeing something that reminds them of trauma, causing them to purposefully go back in thought to the trauma situation or experience an emotion that reminds them of the trauma situation. Finally, the person can return to the traumatizing context or environment and generate the described processes.

\section{Post-Traumatic Stress Disorder Symptoms as Action and Self-Monitoring Problems}

Looking at their everyday action we might find that the patients cannot adequately engage in their actions because their cognitive processes are being interfered with. This could lead to a number of action distortions. We described some of these distortions in suicide attempters [25]. In a routine action such a distraction could lead to unnecessary mistakes. In a new complex action, the problem-solving and learning capacities of the patient could be substantially reduced. It is known that PTSD patients and torture survivors show problems in learning, such as in acquiring a new language [26-29]. In addition, such a dysfunctional cognition as a memory of a negative experience could lead to a negative emotion. Consequently, the action emotion becomes disparate and thus the whole action could be distorted because it is based on a false monitoring of the target situation. Further, the physiological experience of such a negative emotion connected to an action and movement processes that are steered by a different goal with different emotional requirement may lead to painful somatic consequences. Frequent pain occurrence in PTSD diagnosed persons is well documented [30]. Many lower backpain complaints are rooted in such a co-occurrence of physically straining actions performed under disparate negative emotions [31,32]. Example: a divorced woman leaves her three young children with her elderly father at home and begins work in a hotel thousand kilometers away. Making hotel beds while emotionally suffering under her situation of being separated from her young children, she very soon develops excruciating lower back pain. Hence the problem of adequate action congruent emotions and physiological processes or lack of thereof. Another case is when the monitoring processes become distorted and impaired. Information for situation monitoring is not gained from the external cues, but from internal memories and thus the situation monitoring becomes false and a neutral situation could lead to a negative evaluation and could be experienced as threatening. This becomes very dramatic in the case of a flashback when the complete cognitive information is recruited from a previous experience instead of the external information [33,34]. This leads not only to a false interpretation of the situation and to an inadequate emotion, but also to a completely inadequate action. It has been reported that cognitive control is impaired in PTSD diagnosed persons [35].

Another example of a monitoring problem is acting upon an emotional memory instead of on the quick scan of the current situation usually provided by emotional experiencing. 
This is the case, e.g., when we experience an emotion, such as being deserted by a person we feel emotionally close to. This experience however unpleasant should not feel like an existentially threatening situation by an adult person. However, possessing a traumatizing memory of such an experience the new encounter with this emotion would take on the intensity of the traumatizing experience. Thus, the emotional self-monitoring and action monitoring is false. Should the traumatizing experience be connected to pain, when pain became an indication of being killed, any experience of pain could take on an existentially threatening intensity, as experienced in PTSD. Thus, the self-monitoring and action monitoring systems of pain, emotion and awareness or consciousness are involved in the processing of the PTSD symptoms.

\section{Symptoms of PTSD within Projects and Long- Term Pursuits}

The PTSD symptoms are not reduced to short-term action. This is the case in both the traditional PTSD and the complex PTSD acquired over a longer period of time. The patients also complain about their inability to engage in midterm endeavors and about how the trauma experience impacts and changes their whole life. The action theory does not only define short-term actions, but also midterm projects and career or life pursuits conceptualized in an analogous way. Applying this conceptualization to the PTSD symptoms we would also look at the interplay of actions and project, about the constitution and unfolding of projects, their embedding in long term careers and also the processing of such careers.

The persons might not be able to continue to work, to live their life as usual, to call up the vitality, motivation and planning to go on with their usual duties and hobbies. Regular intrusions become feared and future actions avoided. Thus, avoidance is not restricted to certain cues, environmental features, settings or people but could be generalized to any actions because of experiencing and learning the unreliability of one's action. Consequently, whole projects will be distorted and possibly discontinued and thus avoided. How else would PTSD symptoms become a part of a mid-term project? The common conception of complex intrusion in a form of flashback is an automatic response to a stimulus. If a whole action follows it would be a bottom up trigger of a top-down steered action. As the action itself is a top-down steered process, the bottom up trigger would be related to launching a particular project. It could be, e.g., a fear avoidance project. However, intrusions also occur in the form of cognition, emotion and pain as well as sensory experiences. One could also argue that as traumatizing experience is one of failure there is a desire to revisit the situation and relive it, in order to obtain a better result. But, as the revisiting of a traumatizing situation in similar circumstances (prolonged exposure occurs in partly changed circumstances) is very stressful - the original stressful experience is repeated - the person is not able to perform better because of the limitation of available skills under stress. Thus, the revisiting of the traumatizing situation becomes a repeating of the traumatizing situation with the same results. Because of the emotional consequences of such revisiting, this recall is kept short and therefore cannot de- velop the healing properties known from prolonged exposure $[36,37]$. The most important insight is that such intrusion is neither a consequence of a perceived external stimulus nor of coincidentally appearing memory but is a part of a person's turning to traumatic experience with the desire to repair it. Thus, it becomes an agentic process. However, the detrimental consequences of this repeated experience on a mid-term engagement in life is an unwanted consequence. Nevertheless, the involvement in such revisiting of the traumatizing situation and experience becomes a task consuming energy and the time of the person. It is a way of coping with the traumatic experience that again could be seen in terms of intentional behavior, not only as goal-directed actions but also as a goal-directed mid-term project. However, such a project and coping are seldom successful. Thus, intrusion and avoidance can not only be understood as an automatic reaction to the trauma memory, but also as actions and goal-directed midterm projects. The negative changes in mood [38] and cognitions [39] seem to be understandable consequences of these experiences and learning processes.

The emotion or mood, as well as cognitive monitoring, becomes negative in the course of the realistic mirroring of the self and action processes. They are realistic only in as much as they are focused on the trauma related actions and projects, as we have seen, the actions and projects related to intrusion and avoidance.

\section{Are PTSD Symptoms Goal-Directed?}

In considering these views some of the major symptoms of PTSD become more complex than the reactive stimulus conceptualization may suggest. Consequently, in understanding the PTSD symptoms and PTSD diagnosed persons, as well as the existing treatments and devising new ones, we have to be prepared to address the issue of goal-directed processes. Obviously not by informing the PTSD diagnosed persons and expecting them to change.

It is of interest to acknowledge that arousal and reactivity change the PTSD symptom cluster, seemingly the most reactive as mainly physiologically conceived, have to be considered in a more differentiated way, as far as the top-down and bottom up processes are concerned [40]. The hyperarousal is not seen as increased response but an impoverished topdown emotional regulation. In the dissociative subtype PTSD, the emotional top-down regulation the PTSD diagnosed person even showed increased top-down modulation of emotional processes [40].

Thus, it seems that all symptoms of PTSD could be understood in a frame of reference of short-term and long-term goal-directed action processes. A conceptualization encompassing steering, controlling and regulation functions as well as conscious and subconscious processes.

\section{Conceptualization of PTSD and of Its Treat- ment}

PTSD symptoms are often considered as originating in a disorder of memory [41]. In addition, because of the singular dramatic traumatic experience and the intensive symptoms 
of PTSD it has been maintained that the processing of this disorder must be carried by reactive, associative processes anchored in neurobiological changes. Thus, the fear conditioning gained and hold a lot of ground in PTSD theorizing. The classical and operant conditioning processes in development and maintenance of PTSD were described [42] and the role of associative processes stressed [43].

However, the most successful treatment procedure of PTSD, prolonged exposure, is based on the assumption of trauma violating the safety expectations, the cognitive representation of fear [44]. Consequently, an understanding of even such a simple stimulus-response schema of trauma and responses thereof requires involvement of complex cognitive-emotional processes. To solve the tension between the assumption of low order processes of stimulus-response in trauma-flashback and the higher order cognitive processes required for the maintenance and complex dealing with the trauma experiences, a dual representation theory was proposed [45].

Recognizing the role of cognitive appraisal in PTSD and the cognitive coping strategies that play important role in the onset and maintenance of PTSD, a cognitive theory of PTSD was formulated [46]. The oldest theoretical conceptualization of trauma experience, the psychodynamic psychoanalytical theory [47] requires special attention. In the latter the formulated discrepancy between the reactive physiological side of the PTSD symptoms and the meaningful processes of the PTSD maintenance was already visible. Freud's conceptualization of psychological processes in energetic terms, on the one hand, and the descriptions of persons' beliefs about security [48], on the other, documents that.

Thus, the question is how are these disparities in the conceptualization of PTSD symptoms reflected and addressed in the treatment of PTSD. The neurophysiology of the trauma experience, the emotional involvement, the cognitive, but also and unconscious processing of the trauma experience, the stimulus-response and the short-term as well as its longterm nature provide a plethora of possible target windows for treatment of the PTSD and its symptoms.

The prolonged exposure therapy [49], cognitive therapy [50] and EMDR therapy [51] are some of the best evidence-based psychotherapies for PTSD diagnosed persons. The STAIR narrative therapy [52] seems to well integrate these conceptualizations, as well as many of the procedures included and devised in these approaches. It, first of all, conceptually pays a tribute to the basis treatment situation of the narrative encounter common to all psychotherapies. The authors outline 16 sessions in 2 modules [52], p.283): Module 1: 1: Introduction to treatment, 2: Emotional awareness, 3: Emotion regulation, 4: Emotionally engaged living, 5: Understanding relationship patterns, 6: Changing relationship patterns, 7: Agency in relationships, 8: Flexibility in relationships, Module 2: 9: Motivating and planning for memory work, 10: Introduction to exposure, 11: Deepening exploration of memories and contrasting with the present, 12-15: Exploration of the other affective themes, 16: Closure.

In discussing their theoretical underpinning, the authors stress the role of emotional regulation, its ontogenetic devel- opment, the interpersonal regulation and the emotional and interpersonal competencies.

While many of the treatments based on the mentioned theoretical conceptualizations work and the treatment practice is often eclectic or integrative [53], the theoretical conceptualizations are seldom integrative and their links to the treatment steps are often more experiential than well-reasoned. This could be explicated on the provided example of the 16 sessions of the STAIR narrative therapy. To begin with, the philosophy and the theorizing around narrative conceptualization possesses its own tradition. The reasoning about therapeutic alliance (addressed in the first session) stems from a different school. Awareness research again has a different history. Emotional regulation theorizing looks at its own development. Awareness of positive feelings as a guide to goal identification has been promoted by a different psychological branch of research. Interpersonal schemas and goals were addressed and explicated by a different group of authors. The issue of agency was developed from yet another tradition. The clinical significance of flexibility was discovered using personality conceptualization not required by some of the previously referred to studies. Motivating and planning for memory work, and memory hierarchy are some other specific assumptions not necessarily shared by many of the listed conceptualizations. Prolonged exposure, an important part of the treatment, stems from the behavioral therapy that is distant to some of the above assumptions. Closing with discussion on gained skills and changes in schemas and on future goals might sound very plausible, but such plausibility would require a different esteem of common-sense psychology than provided by many of the conceptualizations addressed above. But, nevertheless, why change a winning horse? A question often dealt with [54].

As stipulated above, one of the most effective treatment procedures in dealing with PTSD is prolonged exposure. Researchers have developed several theories about the mechanism of change in exposure-based treatment. These include habituation, cognitive, coping, inhibitory learning, and acceptance and commitment therapy (ACT) models [55-59]. These cover the whole span from the low behavioral organization addressed in habituation processes over cognitive and coping processes to the meaning and value-oriented acceptance and commitment therapy. Thus, the conceptualization of prolonged exposure shares the destiny of the PTSD conceptualization as a whole. The treatment conceptualization is, though probably covering the whole spectrum, defined by certain processes assumed decisive: associative, cognitive behavioral, meaning and value oriented.

It is as if there were in spaghetti sauce cooking a school of onion, a school of garlic, a school of tomatoes, a school of basil and an oregano approach. Obviously, there would be critics indicating the necessity of salt and pepper. They are always right! But the most important lesson is that it is all of the above! Thus, the conceptualization of the PTSD, understanding of the PTSD development relevant processes, the conceptualization of PTSD treatment and understanding 
of the prolonged exposure require an integrative approach to the understanding of human behavior. This has been offered in the conceptualization of contextual goal-directed action.

\section{PTSD: Behavior and Cognition or an Action?}

Addressing the disparities mentioned above we can underline some of the conceptual and empirical suggestions and changes the conceptualization of human behavior went through in last few decades. The conceptualization of motor and goal-directed action, as well as of cognitive processes, including embodied cognition [60], changed substantially [61]. It has been suggested that the motor cortex impacts cognitive processes [62]. It seems to be established that not only cognitive and emotional processes, but also motor processes build a part of the ongoing neurological unfolding of an action [6266]. Further, in conceptualizing embodied and enacted cognition it has been proposed that cognitive processes cannot be understood without considering their embedding in motor processes [67].

These findings and propositions indicate that an integrative conception of human behavior is required. Such a view would also enable us to integrate the different views of PTSD, the different theories and the eclectic suggestions in devising an intervention strategy (we recall the spectrum from conditioning processes to meaning generating responses, from subconscious learning to cognitive restructuring and coping, from short term reactions to ongoing life-long destructive engagement).

Finally, it also has been stressed that rehabilitating patients after a neurological event through passive movements, the movements accompanying cognitions as occurring in an action, have also to be invoked $[68,69]$. Further, relationships between cognitive and motor deficits are increasingly being identified [70].

In addition to integrating cognitive-emotional and motor processes, the integration of higher and lower order of action, action steering, control and regulation, has also been proposed. The hierarchical organization of action, as well as the hierarchical organization of the brain processes have been established $[71,72]$. The co-occurrence of top-down and bottom up processes in various parts of action [73-76] and neurological functioning [77-79] has also been well outlined.

\section{Dissociation and Disconnect In PTSD}

These are some of the issues supporting a new reconsideration of the PTSD conceptualization.

This is not because these issues are of a philosophical nature but because of another issue which will be discussed further. There is the opinion that PTSD manifests itself in a disconnection of brain structures and that patients with chronic PTSD show increased functional brain network segregation [80].

The suggestion of a disconnect issue in PTSD has a long tradition [81]. Nevertheless, it seems that the suggested disconnect in PTSD, indicated in neurological structures and functions was not well outlined as a psychological phenome- non. Only when dealing with the most successful PTSD treatment procedure, the prolonged exposure (PE), the assumption of PTSD being a disconnect disorder seems to be prevalent. PTSD results in a disrupted network of interconnected regions, and PE has been shown to increase the connectivity within and between these regions [82]. Cardena and Carlson [83] suggested that a sense of experiential disconnectedness may include distortions in perceptions about the self or the environment. Thus, the argument of disconnect, be it in brain or psychological functions, seems to be central to the understanding and treatment of PTSD. The issue of disconnect is addressed in the conception or idea of dissociation. The relating of dissociation and trauma experience or PTSD is an old and extensive area of conceptualization and research [84]. The authors conclude their comprehensive review of the empirical literature from the past 25 years maintaining that there is a "clear and consistent evidence that: (1) Dissociation is moderately related to trauma exposure and severity; (2) Dissociation symptoms rise sharply immediately after trauma exposure, then gradually decline for most, but stay high for some; (3) Dissociation is clearly, consistently, and very strongly related to the presence and severity of DSM-IV PTSD symptoms; (4) The presence of high dissociation raises the probability of the presence and high levels of PTSD symptoms; and (5) Dissociative symptoms relate as strongly to the three PTSD symptom clusters as they do to one another." (p. 487).

Despite the strong identification of PTSD with dissociative states or processes a simple literature search shows that publications on PTSD and on dissociation overlap only marginally. In PsycINFO (8.5.19) we found PTSD mentioned in 38220 and dissociation in 21857 cases. PTSD and dissociation occurred together only in 1859 cases, compared to depression that was mentioned in 11752 cases in which PTSD was also addressed. Despite this independent coexistence of PTSD and dissociation the conviction of a disconnect in PTSD prevails.

It has been suggested that there are numerous questions to be answered before the plausible concept of dissociation could be attributed any meaningful explanatory strength [84]. One of the most trivial sounding but relevant questions is "dissociation from what?".

Not only the independent research dealing with PTSD and dissociation, but also the lack of specificity of dissociative phenomena for PTSD indicate the shortcomings of the definitory and explanatory power of dissociation for PTSD. It has been observed that a disconnect or a missing unifier is often taken as the most relevant issue in many psychiatric disorders, such as schizophrenia [85]. In fact, it is one of the oldest conceptualizations of mental illness in modern times [86].

Thus, the concepts of unity of the conscious experience, self and environment, self and others, personality, psychological processes, brain functions or even healthy functioning etc. are much too diffuse to be helpful for a specific analysis of the PTSD processes.

The assumption of a well-connected, integrated unified brain has to have a conceptual equivalent in the psychological realm. We propose that the concept of action achieves just that. 


\section{Conclusions}

One of the concepts that is well defined at a psychological and neurological level is the concept of intentional or goal-directed action. As indicated above, the theory of goal-directed action [22] and the contextual action theory $[12,13]$ might provide some of the specification of the processes involved in trauma experience, PTSD development, maintenance and treatment. The neurological research on intentional action, on the other hand, also indicates the order assumed and described in the action theory [87]. A single feature that disqualifies many of the assumptions about a unifier, dissociation and disconnect is the knowledge that decisions on whether to act require higher interhemispheric cooperation.

Thus, the unity becomes a hierarchical order of action as described in the above-mentioned action theory.

\section{Conflict of Interests}

No.

\section{References}

1. Schnyder U, Cloitre M (2015) Evidence based treatments for trauma-related psychological disorders. Springer, Cham.

2. Schnyder U, Valach L, Hofer D (1996) Trauma-related disorders in psychiatrists' and general practitioners' private practice in Switzerland. J Trauma Stress 9: 631-641.

3. Schnyder U, Valach L (1996) Psychotraumatologie in der ärztlichen Praxis - eine Umfrage. Zeitschrift für ärztliche Fortbildung 90: 347-354.

4. Schnyder U, Valach L (1997) Suicide attempters in a psychiatric emergency room population. Gen Hosp Psychiatry 19: 119-129.

5. Schnyder U, Valach L (1997) Traumatic stress issues in psychiatric institutions in Switzerland. The European Journal of Psychiatry 11: 162-172.

6. Frey C, Valach L (1996) Counselling, therapy and treatment of tortured refugees. International Journal of Psychology 31: 96.

7. Frey C, Valach, L (1997a) The Swiss Red Cross therapy centre for torture victims in Berne, Switzerland. Torture 7: 21-23.

8. Frey C, Valach L (1997b) War and torture traumatized patients in the Swiss Red Cross Therapy Centre. ESTSS Bulletin 4: 2-4.

9. Valach $L$ (2000) Identification of torture victims among refugees. Torture 4: 122-123.

10. Valach L (2005) Suicide ideation in torture and war survivors undergoing psychotherapy. In: JR Rogers, Suicide 2004: Proceeding of the $37^{\text {th }}$ Annual Conference of the American Association of Suicidology. American Association of Suicidology, Washington, DC, 43-47.

11. Valach L (2018a) SCL-90-R and suicide ideation in torture and war survivors receiving psychotherapy. Journal of Cognitive Behavioral Therapy.

12. Valach L, Young RA, Lynam, MJ (2002) Action theory. A primer for applied research in the social sciences. Praeger, Westport, CT.

13. Young RA, Domene JF, Valach, L (2015) Counseling and action. Toward life-enhancing work, relationship, and identity. Springer, New York.
14. American Psychiatric Association (2013) Diagnostic and statistical manual of mental disorders. ( $5^{\text {th }}$ edn), American Psychiatric Publishing, Arlington, VA.

15. Shevlin M, Hyland P, Karatzias T, et al. (2017) Examining the disconnect between psychometric models andclinical reality of posttraumatic stress disorder. Journal of Anxiety Disorders 47: 54-59.

16. Rosen GM, Lilienfeld SO (2008) Posttraumatic stress disorder: An empirical evaluation of core assumptions. Clin Psychol Rev 28: 837-868.

17. Fang SC, Schnurr PP, Kulish AL, et al. (2015) Psychosocial functioning and health-related quality of life associated with posttraumatic stress disorder in male and female Iraq and Afghanistan war veterans: The VALOR registry. J Women's Health 24: 1038-1046.

18. Vogt D, Smith BN, Fox AB, et al. (2017) Consequences of PTSD for the work and family quality of life of female and male U.S. Afghanistan and Iraq War veterans. Soc Psychiatry Psychiatr Epidemiol 52: 341-352.

19. Sripada RK, Henry J, Yosef M, et al. (2018) Occupational functioning and employment services use among VA primary care patients with posttraumatic stress disorder. Psychol Trauma 10: 140-143.

20. Dornbach-Bender A, Ruggero CJ, Schuler K, et al. (2019) Positive and negative affect in the daily life of world trade center responders with PTSD: An ecological momentary assessment study. Psychol Trauma 12: 75-83.

21. Young RA, Valach, L, Collin A (1996) A contextual explanation of career. In: D Brown, L Brooks, Career Choice and Development. ( $3^{\text {rd }}$ edn), Jossey-Bass, San Francisco, 477-512.

22. von Cranach M, Kalbermatten U, Indermuehle K, et al. (1982) Goal-directed action. Academic Press, London.

23. Kalbermatten U, Valach, L (1985) Methods of an integrative approach for the study of social interaction. Communication and Cognition 18: 281-315.

24. Valach L, von Cranach M, Kalbermatten U (1988) Social meaning in the observation of goal directed action. Semiotica 71: 243259.

25. Valach L, Michel K, Young RA (2016) Suicide as a distorted goal-directed process: Wanting to die, killing, and being killed. J Nerv Ment Dis 204: 812-819.

26. Burriss L, Ayers E, Ginsberg J, et al. (2008) Learning and memory impairment in PTSD: Relationship to depression. Depress Anxiety $25: 149-157$.

27. Johnsen GE, Kanagaratnam P, Asbjørnsen AE (2008) Memory impairments in posttraumatic stress disorder are related to depression. J Anxiety Disord 22: 464-474.

28. Scheiner DL, Keilp J, Mindt MR, et al. (2014) Verbal learning deficits in posttraumatic stress disorder and depression. J Trauma Stress 27: 291-298.

29. Sumner JA, Hagan K, Grodstein F, et al. (2017) Posttraumatic stress disorder symptoms and cognitive function in a large cohort of middle-aged women. Depress Anxiety 34: 356-366.

30. Carleton RN, Duranceau S, McMillan KA, et al. (2018) Trauma, pain, and psychological distress: Attentional bias and autonomic arousal in PTSD and chronic pain. Journal of Psychophysiology 32: $75-84$ 
31. Dvorak J, Gauchat MD, Valach L, et al. (1988) The outcome of operation for lumbar disc herniation: A 4-17 years follow-up with emphasis on the somatic aspects. Spine 13: 1418-1422.

32. Valach L, Augustiny KF, Dvorak J, et al. (1989) Coping of patients operated for lumbar disc herniation: Psychosocial aspects. German Journal of Psychology 13: 264-265.

33. Iffland B, Neuner F (2016) Trauma and memory. In: G Fink, Handbook of stress: Vol. 1. Stress: Concepts, cognition, emotion, and behavior. Elsevier Academic Press, San Diego, CA, US, 161-167.

34. Jones E, Vermaas RH, McCartney H, et al. (2003) Flashbacks and post-traumatic stress disorder: The genesis of a 20th-century diagnosis. Br J Psychiatry 182: 158-163.

35. Swick D, Honzel N, Turken U (2015) Intact error monitoring in combat veterans with post-traumatic stress disorder. Psychiatry Res 234: 227-238.

36. Foa EB (2011) Prolonged exposure therapy: Past, present, and future. Depress Anxiety 28: 1043-1047.

37. Foa EB, Hembree EA, Rothbaum BO (2007) Prolonged exposure therapy for PTSD: Emotional processing of traumatic experiences. Oxford University Press, New York.

38. Boland M, Rielage JK, Hoyt T (2018) The power of negative mood in predicting posttraumatic stress disorder and alcohol abuse comorbidity. Psychol Trauma 10: 572-575.

39. Brondolo E, Eftekharzadeh P, Clifton C, et al. (2018) Work-related trauma, alienation, and posttraumatic and depressive symptoms in medical examiner employees. Psychol Trauma 10: 689-697.

40. Nicholson AA, Friston KJ, Zeidman P, et al. (2017) Dynamic causal modeling in PTSD and its dissociative subtype: Bottom-up versus top-down processing within fear and emotion regulation circuitry. Hum Brain Mapp 38: 5551-5561.

41. van der Kolk, BA (2007) The history of trauma in psychiatry. In: MJ Friedman, TM Keane, PA Resick, Handbook of PTSD. Science and practice. Guilford Press, New York, 19-36.

42. Keane TM, Zimering RT, Caddell RT (1985) A behavioral formulation of PTSD in Vietnam veterans. Behavioral Therapist 8: 9-12.

43. Lang PJ (1985) The cognitive psychophysiology of emotions: Fear and anxiety. In: AH Tuma, J Maser, Anxiety and the anxiety disorders. Lawrence and Erlbaum Associates, Hillsdale, 131-170.

44. Foa EB, Kozak MJ (1986) Emotional processing of fear: Exposure to corrective information. Psychol Bull 99: 20-35.

45. Brewin CR, Dalgleish T, Joseph S (1996) A dual representation theory of posttraumatic stress disorder. Psychol Rev 103: 670686.

46. Ehlers A, Clark DM (2000) A cognitive model of posttraumatic stress disorder. Behav Res Ther 38: 319-345.

47. Freud S, Breuer J (1895/1987) Studien über Hysterie (Studies on hysteria). Frankfurt.

48. Abraham K (1921) Symposium on psychoanalysis and the war neurosis held at the fifth international psycho-analytical congress. Budapest, September 1918. The International Psycho-Analytical Library 2: 22-29.

49. McLean CP, Asnaani A, Foa EB (2015) Prolonged exposure therapy. In: U Schnyder, M Cloitre, Evidence based treatments for trauma-related psychological disorders: A practical guide for clinicians. Springer International Publishing, Cham, Switzerland.

50. Ehlers A, Wild J (2015) Cognitive therapy for PTSD: Updating memories and meanings of trauma. In: U Schnyder, M Cloitre, Evidence based treatments for trauma-related psychological disorders: A practical guide for clinicians. Springer International Publishing, Cham, Switzerland, 161-187.

51. Shapiro F, Laliotis D (2015) EMDR therapy for trauma-related disorders. In: U Schnyder, M Cloitre, Evidence based treatments for trauma-related psychological disorders: A practical guide for clinicians. Springer International Publishing, Cham, Switzerland, 205-228.

52. Cloitre M, Schmidt JA (2015) STAIR narrative therapy. In: U Schnyder, M Cloitre, Evidence based treatments for trauma-related psychological disorders: A practical guide for clinicians. Springer International Publishing, Cham, Switzerland, 277-297.

53. Schnyder U, Müller J, Maercker A, et al. (2011) Brief eclectic psychotherapy for PTSD: A randomized controlled trial. J Clin Psychiatry 72 : 564-566.

54. Schnyder U (2005) Why new psychotherapies for posttraumatic stress disorder? Psychother Psychosom 74: 199-201.

55. Arch JJ, Abramowitz JS (2015) Exposure therapy for obsessive-compulsive disorder: An optimizing inhibitory learning approach. Journal of Obsessive-Compulsive and Related Disorders 6: 174-182.

56. Benito KG, Walther M (2015) Therapeutic process during exposure: Habituation model. J Obsessive Compuls Relat Disord 6: 147-157.

57. Berman NC, Fang A, Hansen N, et al. (2015) Cognitive-based therapy for OCD: Role of behavior experiments and exposure processes. Journal of Obsessive-Compulsive and Related Disorders 6: 158-166.

58. Conelea CA, Freeman JB (2015) What do therapists and clients do during exposures for OCD? Introduction to the special issue on theory-based exposure process. Journal of Obsessive-Compulsive and Related Disorders 6: 144-146.

59. Twohig MP, Abramowitz JS, Bluett EJ, et al. (2015) Exposure therapy for OCD from an acceptance and commitment therapy (ACT) framework. Journal of Obsessive-Compulsive and Related Disorders 6: 167-173.

60. Rowlands M (2010) The new science of the mind: From extended mind to embodied phenomenology. MIT Press, Cambridge, MA, US.

61. Koziol LF, Budding DE (2009) Subcortical structures and cognition: Implications for neuropsychological assessment. Springer Science + Business Media, New York, NY, US.

62. Leisman G, Moustafa AA, Shafir T (2016) Thinking, walking, talking: Integratory motor and cognitive brain function. Front Public Health 4: 94.

63. Jackson PL, Decety J (2004) Motor cognition: A new paradigm to study self-other interactions. CurrOpin Neurobiol 14: 259-263.

64. Jeannerod M (2001) Neural simulation of action: A Unifying mechanism for motor cognition. Neurolmage 14: S103-S109.

65. Moreau D (2012) The role of motor processes in three-dimensional mental rotation: Shaping cognitive processing via sensorimotor experience. Learning and Individual Differences 22: 354-359.

66. Rizzolatti G, Fadiga L, Gallese V, et al. (1996) Premotor cortex and the recognition of motor actions. Cognitive Brain Research 3: 131-141.

67. Stewart J, Gapenne O, Di Paolo EA (2010) Enaction: Toward a new paradigm for cognitive science. MIT Press, Cambridge, MA. 
68. Diamond A (2015) Effects of physical exercise on executive functions: Going beyond simply moving to moving with thought. Ann Sports Med Res 2: 1011.

69. O'Connell RG, Robertson IH (2011) Plasticity of high-order cognition: A review of experience-induced remediation studies for executive deficits. In: SA Raskin, Neuroplasticity and rehabilitation. Guilford Press, New York, NY, US, 233-256.

70. Barker-Collo, S, Feigin V (2006) The impact of neuropsychological deficits on functional stroke outcomes. Neuropsychol Rev 16: 53-64.

71. Logan GD, Crump MJC (2011) Hierarchical control of cognitive processes: The case for skilled typewriting. In: BH Ross, The psychology of learning and motivation: Advances in research and theory. Elsevier Academic Press, San Diego, CA, US.

72. Ribas-Fernandes JJF, Shahnazian D, Holroyd CB, et al. (2019) Subgoal- and goal-related reward prediction errors in medial prefrontal cortex. J Cogn Neurosci 31: 8-23.

73. Britt MA, Rouet JF (2012) Learning with multiple documents: Component skills and their acquisition. In: JR Kirby, MJ Lawson, Enhancing the quality of learning: Dispositions, Instruction, and Learning Processes. Cambridge University Press, New York, NY, 276-314.

74. Roscoe RD, Becker DV, Branaghan RJ, et al. (2019) Bridging psychology and engineering to make technology work for people. Am Psychol 74: 394-406.

75. Shurygina O, Kristjánsson Á, Tudge L, et al. (2019) Expectations and perceptual priming in a visual search task: Evidence from eye movements and behavior. Journal of Experimental Psychology: Human Perception and Performance 45: 489-499.

76. Tolston MT, Riley MA, Mancuso V, et al. (2019) Beyond frequency counts: Novel conceptual recurrence analysis metrics to index semantic coordination in team communications. Behav Res Methods 51: 342-360.

77. Choi I, Lee JY, Lee SH (2018) Bottom-up and top-down modulation of multisensory integration. Curr Opin Neurobiol 52: 115122.
78. de Wit S, Corlett PR, Aitken MR, et al. (2009) Differential engagement of the ventromedial prefrontal cortex by goal-directed and habitual behavior toward food pictures in humans. J Neurosci 29: 11330-11338.

79. Velichkovsky BM, Krotkova OA, Kotov AA, et al. (2018) Consciousness in a multilevel architecture: Evidence from the right side of the brain. Consciousness and Cognition 64: 227-239.

80. Zhu H, Li Y, Yuan M, et al. (2019) Increased functional segregation of brain network associated with symptomatology and sustained attention in chronic post-traumatic stress disorder. J Affect Disord 247: 183-191.

81. Jordan CS (1984) Psychophysiology of structural imagery in post-traumatic stress disorder. Journal of Mental Imagery 8: 5165.

82. Stojek MM, McSweeney LB, Rauch SAM (2018) Neuroscience informed prolonged exposure practice: Increasing efficiency and efficacy through mechanisms. Front Behav Neurosci 12: 281.

83. Cardena EB, Carlson EB (2011) Acute stress disorder revisited. Annu Rev Clin Psychol 7: 245-267.

84. Carlson EB, Dalenberg C, McDade-Montez E (2012) Dissociation in posttraumatic stress disorder part 1: Definitions and review of research. Psychological Trauma: Theory, Research, Practice, and Policy, 4: 479-489.

85. Berrios GE (2018) The concept of 'dissociation' in psychiatry. RivistaSperimentale di Freniatria: La Rivistadella Salute Mentale 142: 29-50.

86. Pec O, Bob P, Raboch J (2014) Splitting in schizophrenia and borderline personality disorder. PLoS ONE 9: e91228.

87. Breuer J, Freud S (1895) Studies in hysteria. Basic Books, New York.

88. Zapparoli L, Seghezzi S, Scifo P, et al. (2018) Dissecting the neurofunctional bases of intentional action. PNAS 115: 7440-7445.

DOI: $10.36959 / 362 / 475$

Copyright: (C) 2021 Valach L. This is an open-access article distributed under the terms of the Creative Commons Attribution License, which permits unrestricted use, distribution, and reproduction in any medium, provided the original author and source are credited. 